\title{
Molecular and phylogenetic analysis of HIV-I variants circulating in Italy
}

Luigi Buonaguro ${ }^{1}$, Annacarmen Petrizzo1, Maria Tagliamonte ${ }^{1}$, Francesca Vitone ${ }^{2}$, Maria Carla Re ${ }^{2,3}$, Elisabetta Pilotti ${ }^{4}$, Claudio Casoli ${ }^{5}$, Costanza Sbreglia ${ }^{6}$, Oreste Perrella ${ }^{6}$, Maria Lina Tornesello ${ }^{1}$ and Franco M Buonaguro*1

\author{
Address: ${ }^{1}$ Laboratory of Molecular Biology and Viral Oncogenesis \& AIDS Reference Center, Istituto Nazionale Tumori "Fondazione Giovanni \\ Pascale", Naples - Italy, 2Section of Microbiology of the Department of Hematology, Oncologic Science, Anatomical Pathology and Microbiology, \\ University of Bologna, Bologna - Italy, ${ }^{3}$ Interuniversity Consortium, National Institute Biostructure and Biosystem (INBB), Rome - Italy, \\ ${ }^{4}$ Department of Clinical Medicine, Nephrology, and Health Sciences, University of Parma, Parma - Italy, ${ }^{5}$ Department of Clinical Sciences, \\ Infectious Diseases Unit 'L. Sacco', University of Milano - Italy and 'VII Division of Infectious Diseases, Cotugno Hospital, Naples - Italy \\ Email: Luigi Buonaguro - lbuonaguro@tin.it; Annacarmen Petrizzo - annacarmen.petrizzo@tiscali.it; \\ Maria Tagliamonte - mariellatagliamonte@libero.it; Francesca Vitone - vitonfra@yahoo.it; Maria Carla Re - mariacarla.re@unibo.it; \\ Elisabetta Pilotti - elisabetta.pilotti@gmail.com; Claudio Casoli - claudio.casoli@guest.unimi.it; Costanza Sbreglia - drcosty@libero.it; \\ Oreste Perrella - orper.med@iol.it; Maria Lina Tornesello - mltornesello@virgilio.it; Franco M Buonaguro* - irccsvir@unina.it \\ * Corresponding author
}

Published: 10 October 2008

Infectious Agents and Cancer 2008, 3:13 doi:10.1186/1750-9378-3-13

Received: 24 July 2008

Accepted: 10 October 2008

This article is available from: http://www.infectagentscancer.com/content/3/1/13

(C) 2008 Buonaguro et al; licensee BioMed Central Ltd.

This is an Open Access article distributed under the terms of the Creative Commons Attribution License (http://creativecommons.org/licenses/by/2.0), which permits unrestricted use, distribution, and reproduction in any medium, provided the original work is properly cited.

\begin{abstract}
Objective: The continuous identification of HIV-I non-B subtypes and recombinant forms in Italy indicates the need of constant molecular epidemiology survey of genetic forms circulating and transmitted in the resident population.
\end{abstract}

Methods: The distribution of HIV-I subtypes has been evaluated in 25 seropositive individuals residing in Italy, most of whom were infected through a sexual route during the 1995-2005 period. Each sample has been characterized by detailed molecular and phylogenetic analyses.

Results: 18 of the 25 samples were positive at HIV-I PCR amplification. Three samples showed a nucleotide divergence compatible with a non-B subtype classification. The phylogenetic analysis, performed on both HIV-I env and gag regions, confirms the molecular sub-typing prediction, given that I sample falls into the $C$ subtype and 2 into the $G$ subtype. The $B$ subtype isolates show high levels of intra-subtype nucleotide divergence, compatible with a long-lasting epidemic and a progressive HIV-I molecular diversification.

Conclusion: The Italian HIV-I epidemic is still mostly attributable to the B subtype, regardless the transmission route, which shows an increasing nucleotide heterogeneity. Heterosexual transmission and the interracial blending, however, are slowly introducing novel HIV-I subtypes. Therefore, a molecular monitoring is needed to follow the constant evolution of the HIV-I epidemic. 


\section{Introduction}

Human immunodeficiency virus type 1 (HIV-1) shows an extensive genetic variability and can be classified into 9 phylogenetic subtypes (A-K), which are approximately equidistant from one another, and several circulating recombinant forms (CRFs), resulting from recombination events occurring between different HIV-1 subtypes co-circulating in a specific geographic region [1].

The first phase of the HIV epidemic in Italy has been mainly confined to the injecting drug users (IDUs) risk group, with an absolute predominance of HIV-1 B subtype, in accordance with other Western Countries. In particular, among the total AIDS cases reported in the adult population during the period between 1982 and 2006, $56.0 \%$ were IDUs (including also homosexual IDUs) with similar percentages in men and women groups $(57.3 \%$ and $51.5 \%$, respectively) [2]. The annual percentages of AIDS cases reported in IDUs have gradually decreased from $65.8 \%$ in 1987 to $27.6 \%$ in 2006 [2], in part as consequence of prevention programs implemented in Italy to discourage syringe sharing $[3,4]$. In parallel, the overall AIDS cases reported in heterosexual individuals account for the $19.5 \%$ of total epidemic cases, with a significantly higher percentage in the women category compared to men $(41.2 \%$ vs $13.6 \%)$. However, the annual percentage of AIDS cases related to the heterosexual transmission has dramatically increased over the years, becoming in 2006 the most prevalent risk factor for AIDS (40.4\%) [2].

Although almost $25 \%$ of heterosexual individuals diagnosed with AIDS in Italy are partners of long-term HIV-1 infected individuals, carrying a "historical" B-subtype virus, more than $10 \%$ of them are either immigrants from endemic regions for HIV-1 $(6.87 \%)$ or their Italian partners $(3.03 \%)$, while the risk is unidentified for $64 \%$ of them [2]. This epidemiological evidence, based only on the AIDS reported cases and not considering all the HIV-1 infections derived also from travelling abroad, suggests that at least $10 \%$ of the viruses transmitted through heterosexual contacts could potentially belong to non-B subtypes and CRFs. In fact, HIV-1 isolates genetically related to subtypes novel to the Italian epidemic have been recently increasingly identified and described [5-17].

This has been recently reported in other European Countries, with a higher prevalence of non- $B$ subtypes and CRFs due to an older tradition of immigration waves and much tighter historical as well as economic links with countries endemic for HIV-1 infection [18-30].

In this framework, the introduction and the possible spread of different HIV-1 subtypes and/or recombinant forms, which could require the future development of adequate diagnostic, treatment, and prevention strategies, needs to be constantly monitored.

For the present study, 25 HIV-seropositive individuals residing in Italy were enrolled at sentinel Centers, with a HIV-infection diagnosed in the period 1995-2005. The molecular study has been performed on the hypervariable $\mathrm{C} 2-\mathrm{V} 3$ region of the env gene as well as the more conserved 5' region of the gag p17 sequence. Three non-Bsubtype HIV-1 isolates have been identified and phylogenetically classified as C (1 isolate) and G (2 isolates) subtype.

\section{Methods \\ Sample Collection}

Blood samples were collected from 25 HIV-positive individuals attending Italian sentinel Centers in Bologna, Parma and Naples. For all of them, HIV infection was diagnosed during the 1995 to 2005 period, and most participants were infected through sexual contact (18 of 25, $72 \%)$. HIV-1 infection was diagnosed by immunologic methods (ELISA, Western blot), and the viral load was evaluated by viral RNA quantification. The full designation of samples, according to WHO-proposed nomenclature, is CI05.00XE or CI05.00XG, where CI stands for the city of enrolment, 05 stands for the year of study, 00 for the enrolment number and $\mathrm{E}$ (or G) stands for env (or gag). For the sake of simplicity, however, in this paper the samples have been indicated with CI05.01 (i.e. BO05.01).

\section{Polymerase Chain Reaction (PCR)}

Peripheral blood mononuclear cells (PBMCs) were purified from fresh HIV-1-positive blood samples by Leucoprep density gradient centrifugation, and cellular lysates (approximately $6 \times 10^{6}$ cells) were prepared by Proteinase $\mathrm{K}$ digestion at $56^{\circ} \mathrm{C}$.

The quality of target DNA was verified by PCR amplification of the housekeeping p53 cellular gene. The amplification of HIV-1 V3-V5 region of the env gene and p17 region of the gag gene were performed by nested PCR analysis, using $1.5 \times 10^{5}$ cells (corresponding to approximately $1 \mu \mathrm{g}$ of genomic DNA) as a template. The V3-V5 region of the HIV-1 env gene (666 bp) was amplified, as previously described, using the primer pairs ED5-ED12 and ES7-ES8 for the first and the second round of amplification, respectively [31,32]. The p17 region ( $474 \mathrm{bp}$ ) was amplified, as previously described, using the primer pairs CL1028CL1033 and CL1029-CL1032 for the first and the second round of amplification, respectively $[14,33]$.

\section{DNA Sequencing}

Direct sequencing reactions were performed on PCR products purified with a rapid method developed in our laboratory, following the Sequenase protocol (United States 
Biochemical, Cleveland $\mathrm{OH})$, modified in the labelling step (3 minutes on ice) [31,34]. The internal annealing oligonucleotides, V3B and GAG B SENSE (annealing to a $19 \mathrm{bp}$ fragment of the $\mathrm{C} 2-\mathrm{V} 3$ region and a $17 \mathrm{bp}$ of the p17 region, respectively), were used to prime sense sequence reactions. Sequences were then analyzed on $6 \%$ polyacrylamide wedge sequencing gel.

\section{Analysis of Sequences}

The env and gag sequences obtained were aligned. Multiple sequence alignments were performed with the MegAlign application of the Lasergene software (DNASTAR Inc., Madison, WI) using the Clustal method. Phylogenetic trees were generated by using the neighbor-joining method with the PHYLIP software package (version 3.52c; Joseph Felsenstein, University of Washington). Briefly, the SEQBOOT program was carried out to generate 100 data sets that represent randomly re-sampled versions of the input-aligned sequences, to test the reliability of the final tree topology. Evolutionary distances were estimated by the DNADIST program, using either the Kimura 2-parameter method or the maximum likelihood distance method, and the phylogenetic relationships were determined by the NEIGHBOR program. A consensus tree was constructed using the CONSENSE program with the majority rule criterion and was drawn with the NJPLOT application.

\section{Results}

\section{Epidemiologic and clinical parameters}

Overall, 25 HIV-1-seropositive subjects were enrolled in the study. Of them, $32 \%$ ( 8 of 25 ) were heterosexuals, $36 \%$ (9 of 25 ) were male homosexuals, $4 \%$ ( 1 of 25 ) was a bisexual and 28\% (7 of 25) were IDUs. All but 6 subjects were native Italian, with stable or occasional sexual partners of different nationalities. In particular, the enrolled subjects included an Ethiopian (PR06.03), an Albanian (NA05.04), an Ivorian (PR06.05), a Venezuelan (PR06.06) and two Nigerians (NA05.03, PR06.07). The CD4+ counts ranged from 169 to 1387 cells $/ \mathrm{mm}^{3}$ (median, 664 cells $/ \mathrm{mm}^{3}$ ) (Table 1 ).

\section{Amplification of Italian samples by PCR}

The C2-V5 region of the HIV-1 env gene and the p17 region of the gag gene were amplified by nested PCR using primers and conditions previously described [14]. Overall, $60 \%$ of the samples (15 of 25) were positive at the PCR amplification reactions for both env and gag subgenomic regions. However, 64\% of the samples (16 of 25) were positive at the amplification reaction for $e n v$ and $68 \%$ of the samples ( 17 of 25 ) were positive to the amplification reaction for gag. Therefore, one sample (BO07.14) was positive only in env and two samples (NA05.05 e NA05.06) were positive only in gag; the remaining 7 samples were negative to both sub-genomic regions. This result might be the consequence of either mutations in the primers' annealing regions, reducing the melting temperature, or proviral DNA quantity below the threshold of sensibility. An example of the results obtained by nested PCR for $e n v$ (666 bp) and gag (474 bp) is shown in Figure $1 \mathrm{~A}$ and $1 \mathrm{~B}$.

\section{Molecular analysis of env gene}

The nucleotide sequence analysis has been performed on the C2-V3 region of the env gene, directly from the PCR products without a sub-cloning step. The Italian HIV-1 nucleotide sequences, aligned with HIV-1 reference standards of different subtypes, Groups and CRF02_AG, have been aligned with Clustal method, to determine the homology values between the analyzed samples. The results, show an average divergence of $19.66 \%$ within the Italian group, with values ranging from 7.1 to $33.9 \%$ (data not shown). The Italian sequences, showed average divergences of $17.97 \%$ versus standards of B clade; $25.87 \%$ versus standards of other HIV genotypes of Group M; $43.14 \%$ and $48.4 \%$ versus standards of Groups $\mathrm{N}$ and $\mathrm{O}$, respectively (Figure 2A). Nevertheless, specific samples show a $>30 \%$ divergence versus the $\mathrm{B}$ clade, strongly suggesting a non-B clade classification. In particular, the sample PR06.07 shows an average divergence of 15\% versus the CRF02_AG and 23.2\% versus all other clades (Figure 2B); the sample PR06.03 shows an average divergence of $18 \%$ versus the $\mathrm{C}$ clade and $22.7 \%$ versus all other clades (Figure $2 \mathrm{C}$ ). Therefore, the results suggest a B-clade classification for the vast majority of the analyzed Italian sequences and a C-clade and CRF02_AG classification for the latter samples.

\section{Molecular analysis of gag gene}

The nucleotide sequence analysis has been performed on the p17 region of the gag gene, directly from the PCR products without a sub-cloning step. As for the env gene, the HIV-1 nucleotide sequences have been aligned with Clustal method to HIV-1 reference standards of different subtypes, Groups and CRF02_AG, in order to determine the homology values between the analyzed samples. The results show an average divergence of $15.86 \%$ within the Italian group, with values ranging from 10.81 to $29.16 \%$ (data not shown). The Italian sequences, showed average divergences of $16.88 \%$ versus standards of B clade; $25.99 \%$ versus standards of other HIV genotypes of Group $M ; 48.54 \%$ and $44.15 \%$ versus the standards of Groups $N$ and $\mathrm{O}$, respectively (Figure $3 \mathrm{~A}$ ). Nevertheless, specific samples show a $>22 \%$ divergence versus the $\mathrm{B}$ clade, strongly suggesting a non-B clade classification. In particular, the sample PR06.07, also in the gag region, shows an average divergence of $13 \%$ versus the CRF02_AG and $24.34 \%$ versus all other clades (Figure 3B). Similarly, the sample PR06.03, also in the gag region, shows an average divergence of $22 \%$ versus the $\mathrm{C}$ clade and $32.08 \%$ versus 
Table I: Epidemiologic and clinical parameters of enrolled subjects.

\begin{tabular}{|c|c|c|c|c|}
\hline Sample Code & Nationality & Risk Factor & Presumed infection date & $\mathrm{CD} 4+/ \mu \mathrm{I}$ \\
\hline BO07.0I & Italian & HOMOSEX & 2002 & 886 \\
\hline BO07.06 & Italian & IDU & 1998 & 1110 \\
\hline BO07.09 & Italian & HETEROSEX & 1997 & 533 \\
\hline BO07.12 & Italian & HOMOSEX & 1999 & 515 \\
\hline BO07.13 & Italian & IDU & 1995 & 718 \\
\hline BO07.14 & Italian & IDU & 1998 & 659 \\
\hline BO07.18 & Italian & HOMOSEX & 2001 & 1387 \\
\hline BO07.20 & Italian & IDU & 2000 & 515 \\
\hline BO07.23 & Italian & HETEROSEX & 2002 & 765 \\
\hline BO07.24 & Italian & IDU & 2003 & 917 \\
\hline BO07.25 & Italian & HOMOSEX & 2001 & 462 \\
\hline BO07.26 & Italian & IDU & 2000 & 279 \\
\hline NA05.0I & Italian & IDU & 1999 & 664 \\
\hline NA05.02 & Italian & HOMOSEX & 2000 & 427 \\
\hline NA05.03 & Nigerian & HETEROSEX & 2002 & 1203 \\
\hline NA05.04 & Albanian & HETEROSEX & 2003 & 391 \\
\hline NA05.05 & Italian & HETEROSEX & 2005 & 898 \\
\hline NA05.06 & Italian & HOMOSEX & 2005 & 459 \\
\hline PR06.0I & Italian & HOMOSEX & 2001 & 764 \\
\hline PR06.02 & Italian & BISEX & 1999 & 169 \\
\hline PR06.03 & Ethiopic & HETEROSEX & 2002 & 481 \\
\hline PR06.04 & Italian & HOMOSEX & 2000 & 852 \\
\hline PR06.05 & Ivorian & HETEROSEX & 1998 & 1100 \\
\hline PR06.06 & Venezuelan & HOMOSEX & 2001 & 1244 \\
\hline PR06.07 & Nigerian & HETEROSEX & 2001 & 389 \\
\hline
\end{tabular}



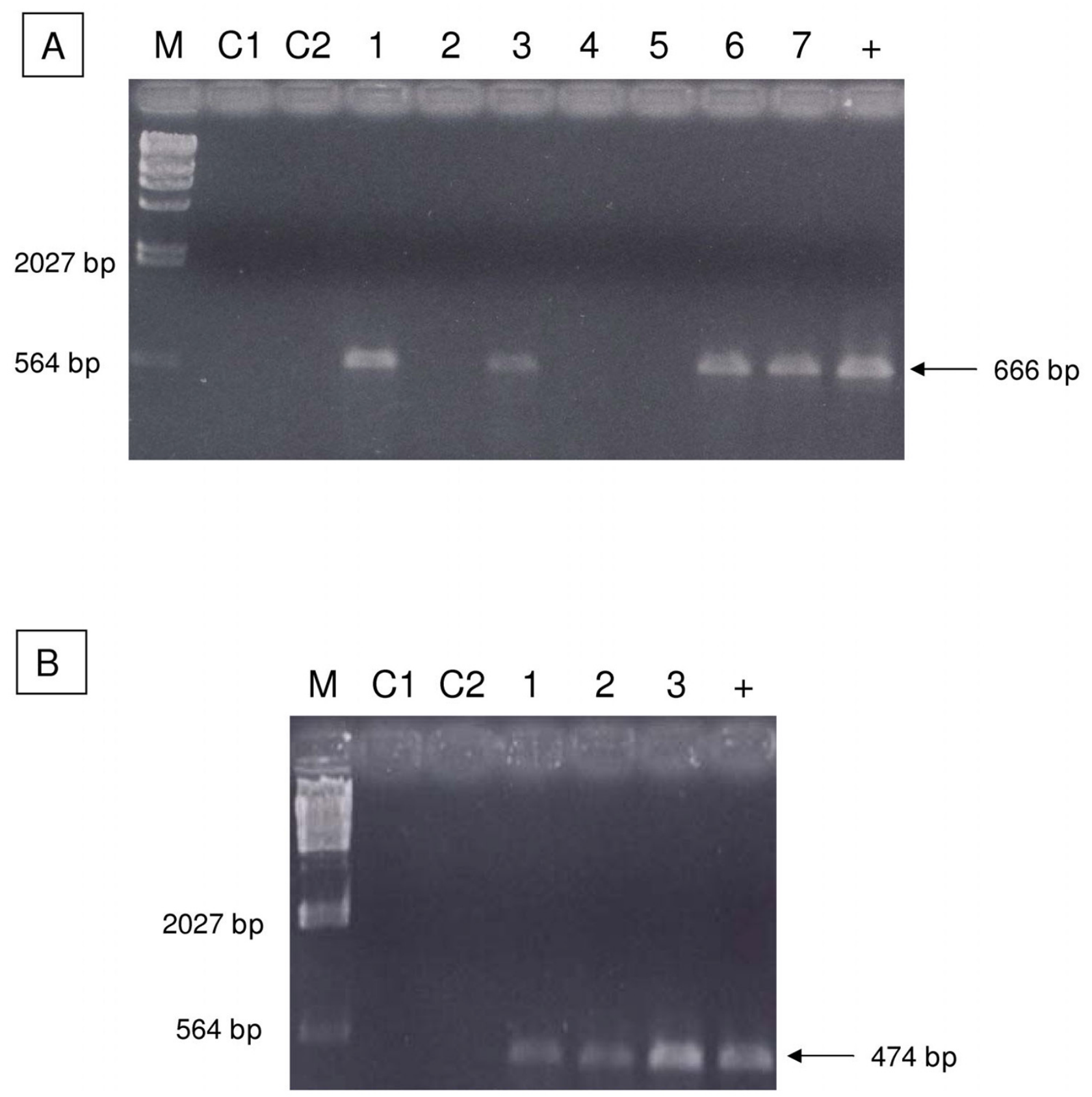

Figure I

Analysis of DNA fragments obtained by nested PCR on the C2-V5 env (A) and the pI 7 gag (B) genes of HIV-I. Examples of specific env fragments of $666 \mathrm{bp}$ (panel A) and gag fragments of $474 \mathrm{bp}$ (panel B), obtained by nested PCR have been separated on a I\% agarose gel. $\mathrm{M}=\lambda / \mathrm{Hind} \mathrm{II}, \mathrm{Cl}=\mathrm{I}$ round negative control; $\mathrm{C} 2=\mathrm{II}$ round negative control; $+=$ positive control. 

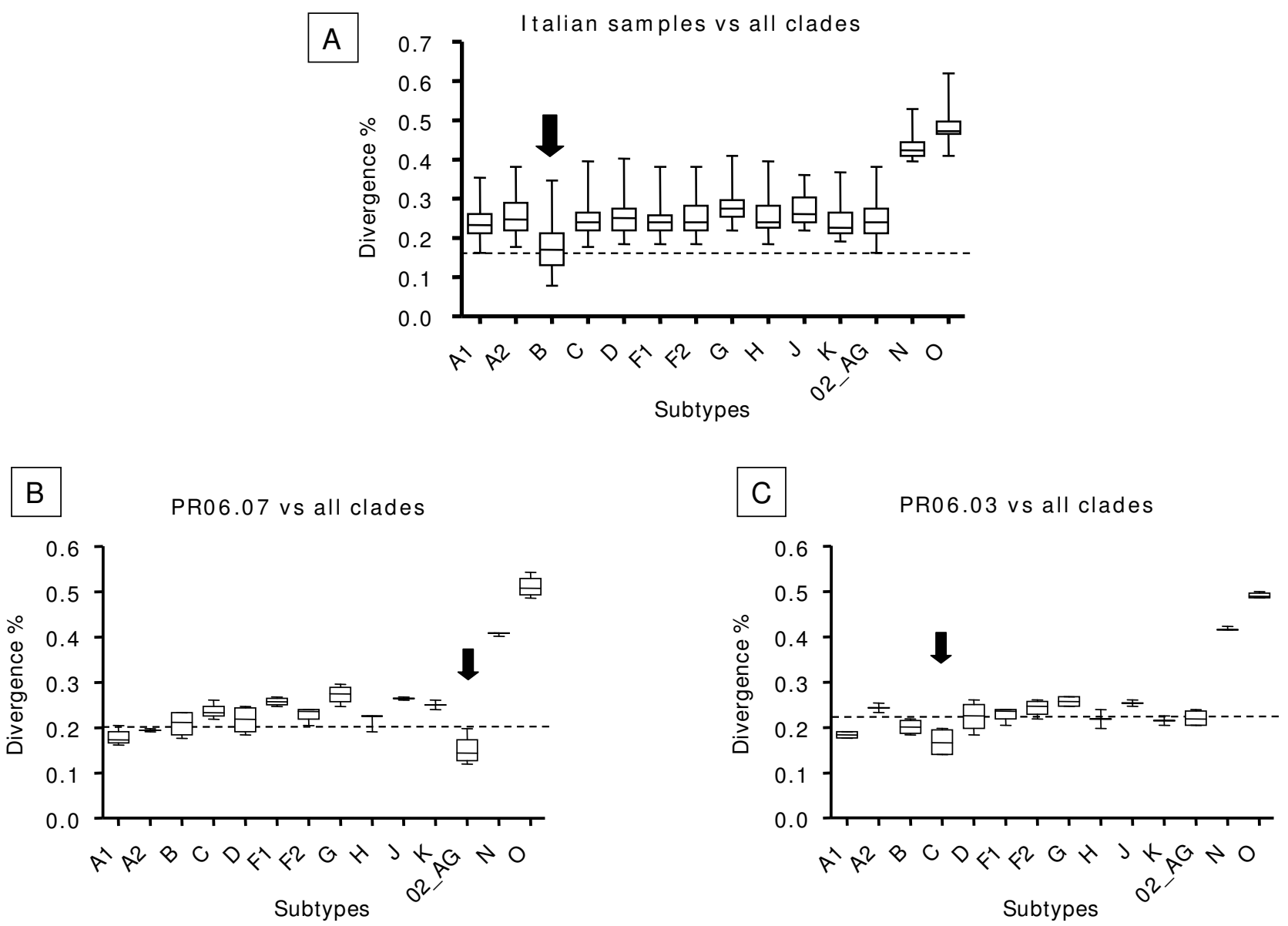

Figure 2

Average nucleotide divergence of C2-V5 env gene versus standard sequences of different clades. The shown average divergence values have been obtained aligning the Italian sequences with standard sequences of individual clades, Groups and CRF02_AG. (A) The lowest average divergence value of the whole group of sequences is versus B standard sequences (arrow); (B) the sample PR06.07 shows the lowest average divergence value versus CRF02_AG standards (arrow); (C) the sample PR06.03 shows the lowest average divergence versus clade $C$ standard sequences $($ arrow $)(P<0.01)$.

all other clades (Figure 3D). Finally, the sample NA05.05, negative for $e n v$, shows an average divergence of $13.9 \%$ versus the CRF02_AG and $25.31 \%$ versus all other clades (Figure 3C). Therefore, also in the gag region, the results suggest a B-clade classification for the vast majority of the analyzed Italian sequences and confirm a C-clade or CRF02_AG classification for the same samples identified in $e n v$.

Phylogenetic analysis of C2-V3 env and p I 7 gag sequences Nucleotide sequences have been pairwise aligned with HIV-1 reference standards of different subtypes and CRFs, discounting gaps due to nucleotide insertions/deletions. The alignments of HIV-1 env and gag nucleotide sequences have been used to generate phylogenetic trees by the neighbor-joining method. Confidence values for individual branches have been determined by a bootstrap analysis. The reference standards of different subtypes as well as CRFs included in this study cluster in the expected distinct phylogenetic branches in both env and gag subgenomic regions, indicating that the length of sequence fragments used in this analysis is sufficient for the identification of known subtypes.

All the Italian HIV-1 isolates showing a rate of nucleotide divergence less than $30 \%$ in env and $20 \%$ in gag versus standards of the B clade, phylogenetically cluster with reference standards of this clade in both env and gag subgenomic regions, forming several sub-clusters. Similarly, the 3 samples showing a lower nucleotide divergence both in env and gag versus standards of the $\mathrm{C}$ clade or the CRF02-AG, cluster with these non-B subtype standards in both sub-genomic regions, confirming the tentative sub- 

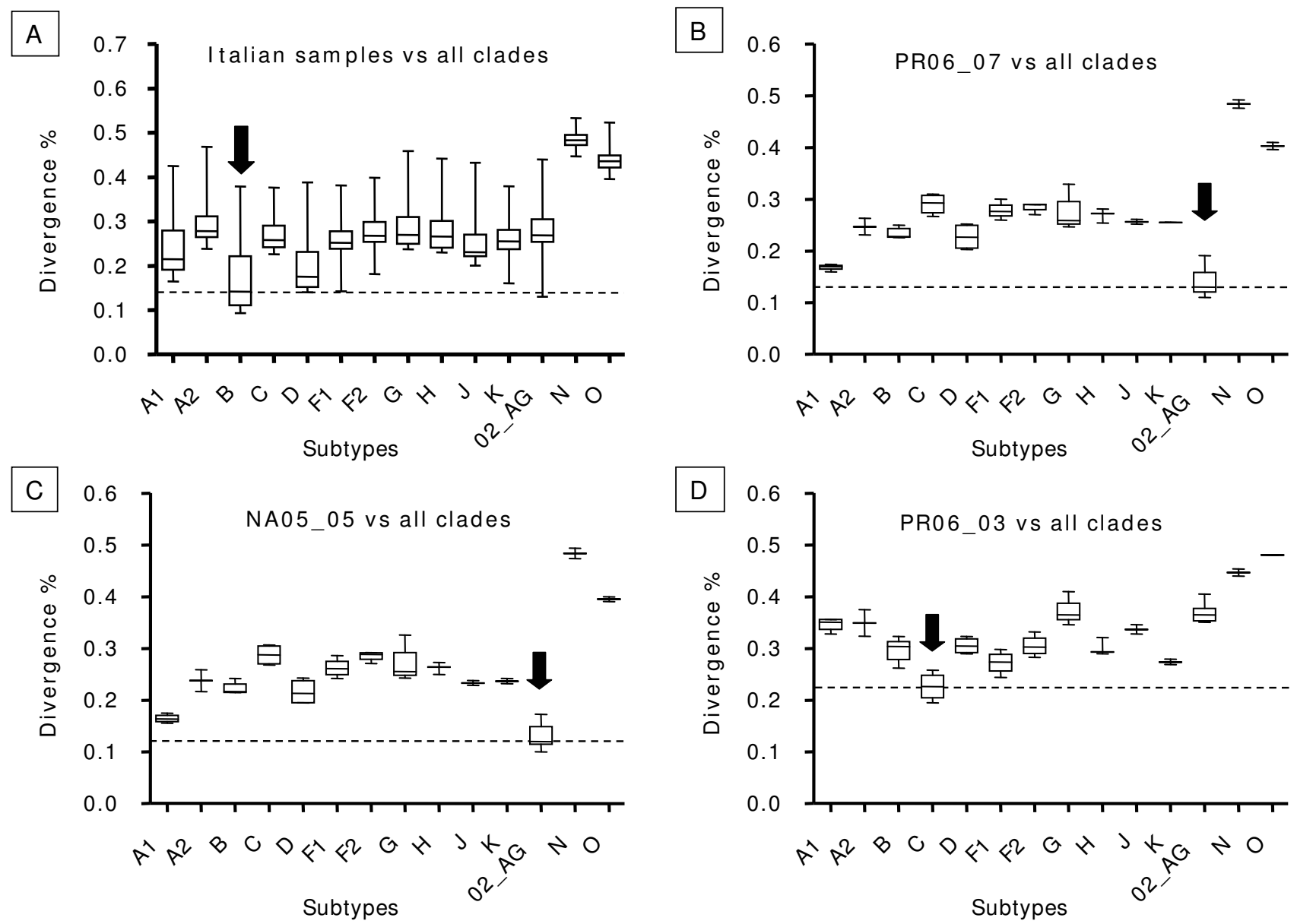

Figure 3

Average nucleotide divergence of pl 7 gag gene versus standard sequences of different clades. The shown average divergence values have been obtained aligning the Italian sequences with standard sequences of individual clades. (A) The lowest average divergence value of the whole group of sequences is versus B standard sequences (arrow); (B) the sample PR06.07 and (C) the sample NA05.05 show the lowest average divergence value versus CRF02_AG standards (arrow); (D) the sample PR06.03 shows the lowest average divergence versus clade $C$ standard sequences (arrow) $(p<0.0 \mathrm{I})$.

type classification based on nucleotide divergence values (Figure 4 and 5).

Moreover, all isolates show a concordant subtype classification in both env and gag sub-genomic regions, suggesting the absence of intra-genomic recombination events.

\section{Peptide analysis and comparison}

The V3 and p17 region amino acid sequences have been deduced for each isolate by computer analysis and aligned following their subtype classification. The V3 region of the Italian B-subtype isolates identified in this study shows an amino acid variability mainly localized outside the V3 loop region. The consensus derived from the alignment, in fact, shows that the amino acid residues conserved in $100 \%$ of the aligned sequences are all localized in the V3 loop ( 9 of $35,25.71 \%$ ). However, besides the subtypespecific "fingerprint" GPGR sequence at the tip of the V3 loop, less-represented sequences have been identified at the tip (GPGG, GPGS, GPGQ), suggesting a constant diversification in the $\mathrm{B}$ clade (Figure 6A).

In regards to the non- $\mathrm{B}$ clade isolates identified in this study, and distributed in two different clades $(C$ and CRF02-AG), the too limited number of samples hampers the possibility to derive a consensus sequence and to infer conclusions; nevertheless, it is worthwhile to mention that they all show the "fingerprint" GPGQ tetramer at the tip of their V3 loop sequences (data not shown).

Moreover, mutations in amino acid residues conferring resistance to fusion/binding inhibitors, in association 


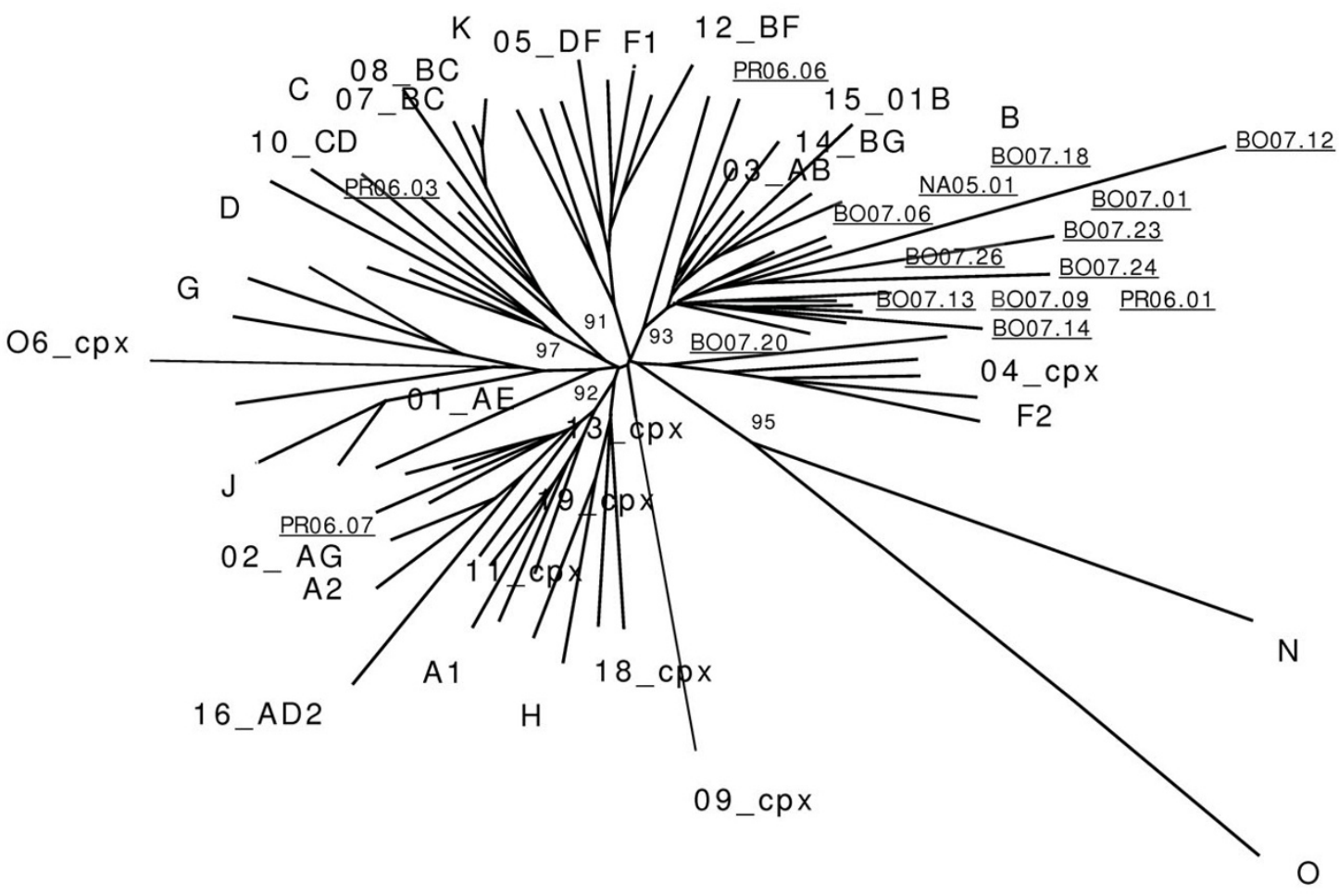

\section{Figure 4}

Phylogenetic classification of the C2-V3 env region. The C2-V3 env region of Italian samples has been aligned with standard sequences of HIV-I group $M$ including some known CRF. Sequences from groups $N$ and $O$ have been used as outgroup. Italian sequences are indicated as underlined. Reliability has been estimated by boot-strap analysis. The bar shows a $10 \%$ divergence.

with other mutations along the env sequence not analyzed in the present study, have been observed (i.e. Q296K), suggesting the transmission of isolates resistant to this class of antiretrovirals (Figure 6A) [35-37].

The $\mathrm{p} 17$ region of the $\mathrm{B}$ clade isolates shows a low aminoacidic variability and the consensus derived from the alignment shows an overall rate of amino acid conservation of $44.44 \%$ (36 of 81 residues). None of the observed amino acid changes is found in gag residues conferring drug resistance (Figure 6B). Similar results are observed also for non-B clade isolates.

\section{Discussion}

A molecular and phylogenetic characterization was performed on HIV-1 variants identified in individuals residing in Italy and infected in the 1995-2005 period. The groups at high risk of HIV-1 infection (heterosexuals, homosexuals and IDUs) were equally represented in the present study. The $\mathrm{C} 2-\mathrm{V} 5$ and $\mathrm{p} 17$ regions of the env and gag gene have been amplified from uncultured PBMCs of
Italian samples by the standardized nested PCR conditions.

Informative regions of the 2 structural gag and env genes have been studied in parallel, to have an immediate picture of the evolution pattern in viral regions under different immune pressure and to identify possible intragenomic recombinants. In fact, considering the worldwide represented CRFs described until now, the p17 gag and the $\mathrm{C} 2-\mathrm{V} 3 \mathrm{env}$ regions show a different subtype designation in most of cases and are highly diagnostic for the identification of novel recombinants.

The average nucleotide divergences versus standard sequences of different subtypes suggest the presence of B and non-B subtypes among the Italian sequences identified in the present study. Moreover, within the B subtype sequences, the average divergence in the env $\mathrm{C} 2-\mathrm{V} 3$ region is $18.08 \%$, with values ranging from 7.1 to $29.9 \%$. On the contrary, the average divergence in the gag $\mathrm{p} 17$ region is $11.13 \%$, with values ranging from 7.79 to $16.86 \%$. These 


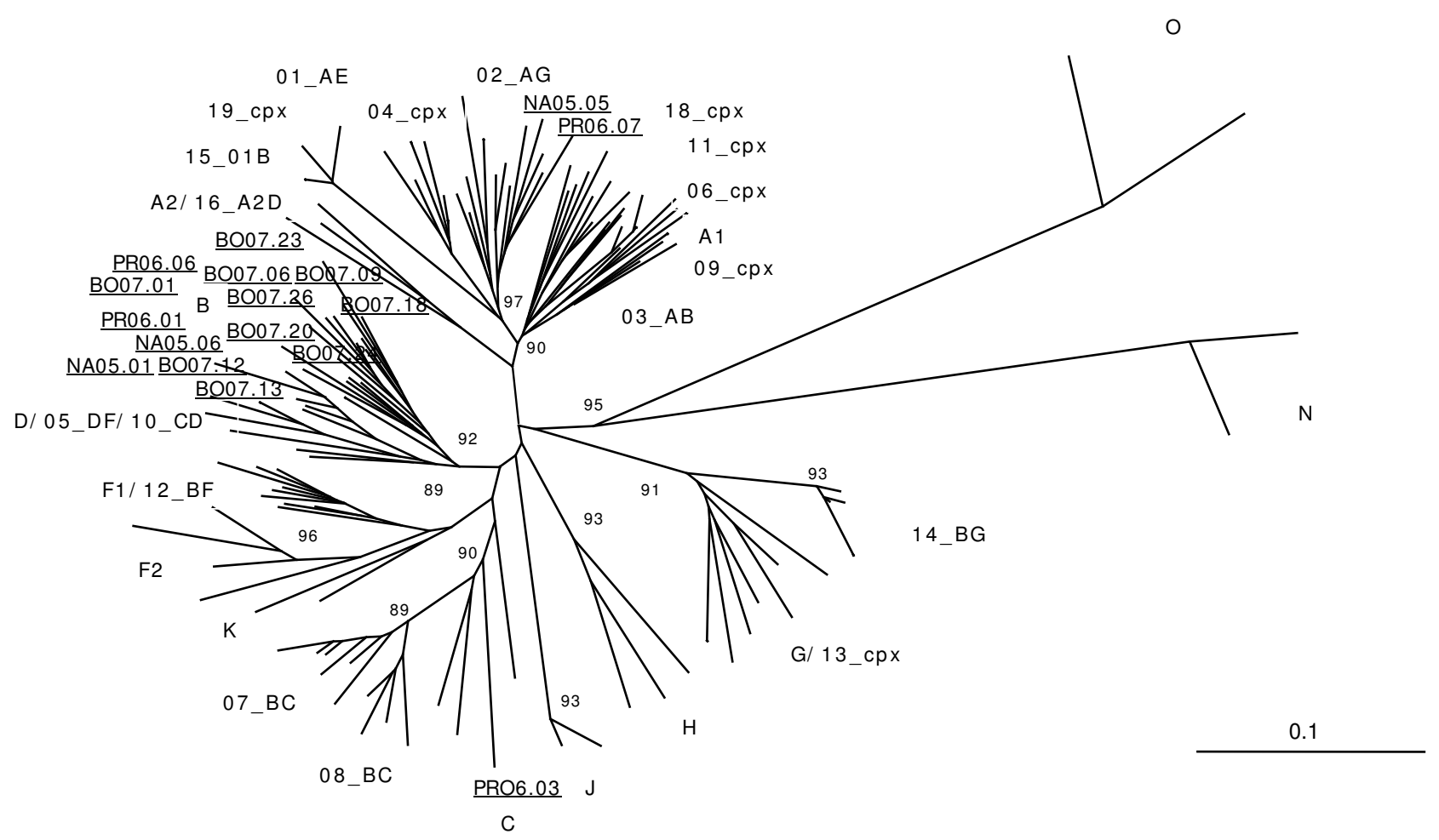

\section{Figure 5}

Phylogenetic classification of the p I 7 region of gag gene. The p I7 region of gag gene from Italian samples has been aligned with standard sequences of HIV-I group $M$ including some known CRF. Sequences from groups $\mathrm{N}$ and $\mathrm{O}$ have been used as outgroup. Italian sequences are indicated as underlined. Reliability has been estimated by boot-strap analysis. The bar shows a $10 \%$ divergence.

observed divergence values are compatible with samples identified in a geographical area characterized by a longlasting HIV epidemic and confirm the more pronounced genetic evolution of env gene compared to gag.

The phylogenetic analysis confirmed the nucleotide divergence subtype prediction for both $\mathrm{B}$ and non-B-subtype classification; in particular, of the 3 non-B isolates, 2 cluster with CRF02-AG (NA05.05 and PR06.07), 1 with the C subtype (PR06.03). Moreover, for all the B- and non-Bsubtype sequences, the phylogenetic classification matches in the gag and $e n v$ sub-genomic regions, suggesting the absence of intra-genomic recombination events.

The phenetic analysis of the $\mathrm{V} 3$ region shows a significant amino acid stability in 9 residues of the V3 loop, for Bsubtype isolates, confirming the strong selection for specific sequences involved in strategic functions regarding the immune response as well as cellular tropism and transmission. The different HIV-1 isolates identified in the current study show the subtype-specific tetrameric sequence at the apex of the V3 loop (GPGR for B clade, GPGQ for non-B clades), which is considered the target for the anti-V3 neutralizing antibodies. However, less-represented sequences have been identified at the tip of the $\mathrm{B}$ clade isolates (GPGG, GPGS, GPGQ), suggesting a constant diversification in this clade.

The overall results suggest that the B subtype is still largely predominant in the HIV-1 epidemic in Italy and is circulating among all risk groups. On the contrary, HIV-1 nonB subtypes in Italy are strictly associated with the heterosexual transmission and are identified in infections acquired in the last period (2001-2005). The three nonB-subtype HIV-1 isolates are strictly associated with heterosexual transmission. The samples PR06.03 and PR06.07, corresponding to an Ethiopian and a Nigerian subject respectively, belong to the subtype/CRF predominant in their respective Country of origin, suggesting an infection either prior to the immigration to Italy or subsequent but through heterosexual contacts with HIV-infected subjects from those Countries. The sample NA05.05, on the contrary, corresponds to an Italian-born subject with a possible partner/s from Regions with high endemicity for HIV infections. 


\begin{tabular}{|c|c|c|}
\hline A & Consensus & CTRPNNNTRK 2 I 2 2GPGR ÄF Y A TG 2 I I GD I R 2 äHC \\
\hline & B007.01 & 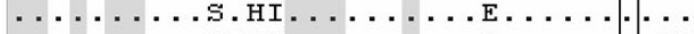 \\
\hline & B007.06 & . . . . . . s. HM. . . . . . . . . \\
\hline & B007.09 & ....G.HM. .G V.QQ.Q. .N. . \\
\hline & B007.12 & $\ldots$. . G.YI. . . QV . .EK. . . . \\
\hline & B007.13 & ....S.QI.........EK... \\
\hline & B007.14 & . . RC $\sim$ TM. . . GE. . TR. E. TRRYKER. I \\
\hline & BO07.18 & $\ldots \ldots$. . . \\
\hline & B007.20 & . .G. . .G.RM. . T. . DR.V.N. \\
\hline & B007.23 & . . . . . A.RSLLL . . S. . V. AD . . . . . FL \\
\hline & B007.24 & . . . . . G. GM. .GSS. . . . . . . \\
\hline & B007.26 & $\ldots$.... I.G.HM.......... QV . . . \\
\hline & NA05.01 & $\ldots \ldots$. . . . . . . . . . \\
\hline & PR06.01 & 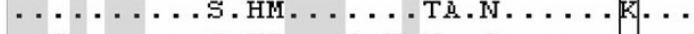 \\
\hline & PR06.06 & .G.....G.HI...Q.V.V..Q... \\
\hline
\end{tabular}

$\mathrm{B}$

\begin{tabular}{|c|c|}
\hline insensus & YCVHQKIDVKD TKEAL? KIE E QNKSKRKAQQA--?---- ? A.A? T GNSSQVSQNYP IVQN? QGQMUHQA I \\
\hline 3007.01 & D. . . . $--\mathrm{A}--\sim \sim \sim-$ G. . NN . \\
\hline 007.06 & - \\
\hline 07.09 & ... . QQA---A.M. TGR. \\
\hline B007.12 & . L . . - - - - - . D. \\
\hline B007.13 & . - ------- . D. \\
\hline 3007.18 & $--------\mathrm{A} . \mathrm{D}$ \\
\hline 007.20 & --------- A. D. \\
\hline B007.23 & $\ldots \sim \sim \sim--$ A. . . G. \\
\hline B007.24 & $\ldots--\mathrm{A}--\sim \sim \sim-\mathrm{D}$. \\
\hline 3007.26 & $\ldots--\mathrm{A}--\sim \sim \sim-\mathrm{D}$. \\
\hline A05.01 & 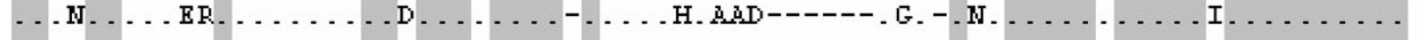 \\
\hline A05.06 & T . . .------- . D \\
\hline R06.01 & N. . . . VLA---KET TL \\
\hline 06.06 & $\ldots$ L . . . . . . \\
\hline
\end{tabular}

\section{Figure 6}

Alignment of the amino acid sequences. (A) V3 env region and (B) p 17 gag region have been aligned, and a consensus sequence (top) has been generated. Question marks (?) have been introduced in the consensus when, in the specific position, no residue is found in more than $50 \%$ of sequences. Dots (.) indicate agreement with the consensus and dashes (-) indicate a gap inserted to maintain the alignment. Gray areas indicate perfectly conserved residues. Boxed residues indicate mutations possibly conferring resistance to class of drugs.

These results confirm that in Italy, as in other Western European countries, non-B subtypes or recombinant forms are introduced by immigrants/migrants and transmitted at a low rate to the indigenous population. This would also explain the lower prevalence of non-B subtypes in Italy compared with other European countries with an older tradition of immigration waves and much tighter historic and economic links with African countries.

The presented data are representative of a nationwide molecular survey and, regardless the small sample size, are part of recurrent studies giving a constant updated picture of the genetic evolution of the HIV-1 epidemics in different risk groups in Italy.

\section{Competing interests}

The authors declare that they have no competing interests.

\section{Authors' contributions}

LB supervised the molecular and phylogenetic analysis and wrote the paper; AP and MT conducted molecular and phylogenetic analysis; FV and MCR enrolled patients and collected samples in Bologna; EP and CC enrolled patients and collected samples in Parma; CS and OP enrolled patients and collected samples in Naples; MLT contributed to the phylogenetic analysis and to writing the paper; FMB supervised the whole project. All authors read and approved the final manuscript. 


\section{Acknowledgements}

This study was supported by grant from the Ministero Italiano della Sanità (Ricerca Corrente; Progetto Finalizzato AIDS 2006, \#20G. 19 and the SIVIM study group for DNA test standardization). The GenBank accession numbers for the sequences included in this manuscript are FJ447882 to FJ447897, for the env sequences, and FJ447898 to FJ4479I6, for the gag sequences.

\section{References}

I. Buonaguro L, Tornesello ML, Buonaguro FM: Human immunodeficiency virus type I subtype distribution in the worldwide epidemic: pathogenetic and therapeutic implications. J Virol 2007, 81 : 10209-10219.

2. Italian AIDS Operative Center: Aggiornamento dei casi di AIDS notificati Italia - Dec 2006. Not Ist Sup Sanità 2007, 20(SI):

3. Nicolosi A, Molinari S, Musicco M, Saracco A, Ziliani N, Lazzarin A: Positive modification of injecting behavior among intravenous heroin users from Milan and Northern Italy: I987- 1989. BrJ Addiction I991, 86:91-102.

4. Rezza G, De Rose A, Dorrucci M, Arpino C, Serafin I: Declining prevalence of HIV infection among injecting drug users entering drug treatment in Italy: 1990-1991. Eur J Epidemiol 1993, 9:663-666.

5. Balotta C, Violin M, Monno L, Bagnarelli P, Riva C, Facchi G, Berlusconi A, Lippi M, Rusconi S, Clementi M, Galli M, Angarano G: Prevalence of multiple dideoxynucleoside analogue resistance (MddNR) in a multicenter cohort of HIV-I-infected Italian patients with virologic failure. J Acquir Immune Defic Syndr 2000, 24(3):232-240.

6. Balotta C, Facchi G, Violin M, Van Dooren S, Cozzi-Lepri A, Forbici F, Bertoli A, Riva C, Senese D, Caramello P, Carnevale G, Rizzardini G, Cremonini L, Monno L, Rezza G, Perno CF, Ippolito G, d'ArminioMonforte A, Vandamme AM, Moroni M: Increasing prevalence of non-clade B HIV-I strains in heterosexual men and women, as monitored by analysis of reverse transcriptase and protease sequences. J Acquir Immune Defic Syndr 200 I, 27(5):499-505.

7. Ceccherini-Silberstein F, Erba F, Gago F, Bertoli A, Forbici F, Bellocchi MC, Gori C, d'Arrigo R, Marcon L, Balotta C, Antinori A, Monforte $A D$, Perno CF: Identification of the minimal conserved structure of HIV-I protease in the presence and absence of drug pressure. AIDS 2004, I8:FII-FI9.

8. Monno L, Brindicci G, Lo CS, Punzi G, Scarabaggio T, Riva C, Di BC, Pierotti P, Saracino A, Lagioia A, Mazzotta F, Balotta C, Angarano G: HIV-I subtypes and circulating recombinant forms (CRFs) from HIV-infected patients residing in two regions of central and southern Italy. J Med Virol 2005, 75:483-490.

9. Venturi G, Romano L, Carli T, Corsi P, Pippi L, Valensin PE, Zazzi M: Divergent distribution of HIV-I drug-resistant variants on and off antiretroviral therapy. Antivir Ther 2002, 7(4):245-250.

10. Bagnarelli P, Vecchi M, Burighel N, Bellanova D, Menzo S, Clementi $M$, De RA: Genotypic and phenotypic correlates of the HIV Type I env gene evolution in infected children with discordant response to antiretroviral therapy. AIDS Res Hum Retroviruses 2004, 20:1306-1313.

11. Binley JM, Wrin T, Korber B, Zwick MB, Wang M, Chappey C, Stiegler G, Kunert R, Zolla-Pazner S, Katinger H, Petropoulos CJ, Burton DR: Comprehensive cross-clade neutralization analysis of a panel of anti-human immunodeficiency virus type I monoclonal antibodies. J Virol 2004, 78: I 3232-I 3252.

12. Tramuto F, Vitale F, Bonura F, Romano N: Detection of HIV type I non-B subtypes in Sicily, Italy. AIDS Res Hum Retroviruses 2004, 20:25I-254.

13. Buonaguro L, Tagliamonte M, Tornesello ML, Ciuffreda D, Capiluppi B, Lopalco L, Lazzarin A, Tambussi G, Buonaguro FM: Molecular and phylogenetic characterization of HIV variants in Italian primary HIV infections (PHI): identification of non-B subtype variants. J Biol Regul Homeost Agents 2002, I6(I):44-48.

14. Buonaguro L, Tagliamonte M, Tornesello ML, Pilotti E, Casoli C, Lazzarin A, Tambussi G, Ciccozzi M, Rezza G, Buonaguro FM: Screening of HIV-I isolates by reverse Heteroduplex Mobility Assay and identification of non-B subtypes in Italy. J Acquir Immune Defic Syndr 2004, 37(2): 1295- I 306.
15. Buonaguro L, Tagliamonte M, Tornesello ML, Buonaguro FM: Evolution of the HIV-I V3 region in the Italian epidemic. New Microbiol 2007, 30(I): I-II.

16. Buonaguro L, Tagliamonte M, Tornesello ML, Buonaguro FM: Genetic and phylogenetic evolution of HIV-I in a low subtype heterogeneity epidemic: the Italian example. Retrovirology 2007, 4:34.

17. Tagliamonte M, Vidal N, Tornesello ML, Peeters M, Buonaguro FM, Buonaguro L: Genetic and phylogenetic characterization of structural genes from non-B HIV-I subtypes in Italy. AIDS Res Hum Retroviruses 2006, 22:1045-105I.

18. Snoeck J, Van Dooren S, Van Laethem K, Derdelinckx I, Van Wijngaerden E, De Clercq E, Vandamme AM: Prevalence and origin of HIV-I group $M$ subtypes among patients attending a Belgian hospital in 1999. Virus Research 2002, 85:95-107.

19. Fransen K, Buvé A, Nkengasong JN, Laga M, Groen G van der: Longstanding presence in Belgians of multiple non-B HIV-I subtypes. Lancet 1996, 347: 1403.

20. Iversen AKN, Learn GH, Fugger L, Gerstoft J, Mullins Jl, Skinhoj P: Presence of multiple HIV subtypes and a high frequency of subtype chimeric viruses in heterosexually infected women. J Acquir Immune Defic Syndr 1999, 22(4):325-332.

21. Leitner T, Escanilla D, Marquina S, Wahlberg J, Brostrom C, Hansson $\mathrm{HB}$, Uhlen M, Albert J: Biological and molecular characterization of subtype $D, G$, and A/D recombinant HIV-I transmission in Sweden. Virology 1995, 209: I36-146.

22. Boni J, Pyra H, Gebhardt M, Perrin L, Burgisser P, Matter L, Fierz W, Erb P, Piffaretti JC, Minder E, Grob P, Burckhardt JJ, Zwahlen M, Schupbach J: High frequency of non-B subtypes in newly diagnosed HIV-I infections in Switzerland. J Acquir Immune Defic Syndr 1999, 22(2): 174-179.

23. Couturier E, Damond F, Roques P, Fleury HJ, Barin F, Brunet JB, BrunVezinet F, Simon F: HIV-I diversity in France, 1996-1998. The AC I I laboratory network. AIDS 2000, 14:289-296.

24. Paraskevis D, Magiorkinis E, Theodoridou M, Mostrou G, Papaevangelou V, Kiosses VG, Hatzakis A, Matsianotis N: Molecular epidemiology of vertical human immunodeficiency virus type I transmission in Greece: evidence of non-B subtypes. I Hum Virol 1999, 2(6):239-243.

25. Devereux H, Loveday C, Burke A, Dann L, Johnson M, Phillips A: The prevalence of non-B subtype HIV-I in a London HIVIAIDS outpatient clinic. AIDS 1999, 13:142.

26. Holguin A, Alvarez A, Soriano V: HIV-I subtype J recombinant viruses in Spain. AIDS Res Hum Retroviruses 2002, 1 8:523-9.

27. Holguin A, Alvarez A, Soriano V: High prevalence of HIV-I subtype $G$ and natural polymorphisms at the protease gene among HIV-infected immigrants in Madrid. AIDS 2002, 16:1163-70

28. Falkensammer B, Doerler M, Kessler HH, Puchhammer-Stoeckl E, Parson W, Duftner C, Dierich MP, Stoiber H: Subtype and genotypic resistance analysis of HIV-I infected patients in Austria. Wien Klin Wochenschr 2007, I 1 9:18I-I85.

29. Vidal N, Frange P, Chaix ML, Mulanga C, Lepira F, Bazepeo SE, Goujard C, Meyer L, Rouzioux C, Delaporte E, Peeters M: Characterization of an Old Complex Circulating Recombinant Form, CRF27_cpx, Originating from the Democratic Republic of Congo (DRC) and Circulating in France. AIDS Res Hum Retroviruses 2008, 24:3 315-32I.

30. Holguin A, Lospitao E, Lopez M, de Arellano ER, Pena MJ, del RJ, Martin C, Soriano V: Genetic characterization of complex interrecombinant HIV-I strains circulating in Spain and reliability of distinct rapid subtyping tools. J Med Virol 2008, 80:383-39I.

31. Buonaguro L, Del Gaudio E, Monaco M, Greco D, Corti P, BethGiraldo E, Buonaguro FM, Giraldo G: Heteroduplex mobility assay and phylogenetic analysis of $\mathrm{V} 3$ region sequences of HIV I isolates from Gulu - Northern Uganda. J Virol 1995, 69(I 2):797|-798|.

32. Naderi HR, Tagliamonte M, Tornesello ML, Ciccozzi M, Rezza G, Farid R, Buonaguro FM, Buonaguro L: Molecular and phylogenetic analysis of HIV-I variants circulating among injecting drug users in Mashhad-Iran. Infectious Agents and Cancer 2006, I:4.

33. Buonaguro L, Tagliamonte M, Tornesello ML, Buonaguro FM: Evaluation of a modified version of Heteroduplex Mobility Assay for rapid screening of HIV-I isolates in epidemics characterized by mono/dual clade predominance. J Virol Methods 2005, 124:123-134. 
34. Buonaguro L, Greco D, Tornesello ML, Rago M, Zaccarelli M, Curcio F, Sguazzo N, Pipolo G, Beth-Giraldo E, Buonaguro FM, Giraldo G: Analysis of HIV-I env gene V3 loop sequence in a southern italian cohort of intravenous drug users. AIDS 1994, 8:268-269.

35. Kanbara K, Sato S, Tanuma J, Tamamura H, Gotoh K, Yoshimori M, Kanamoto T, Kitano M, Fujii N, Nakashima $\mathrm{H}$ : Biological and genetic characterization of a human immunodeficiency virus strain resistant to CXCR4 antagonist TI34 I I. AIDS Res Hum Retroviruses 2001, I7:615-622.

36. De VK, Reymen D, Griffin P, Steinkasserer A, Werner G, Bridger GJ, Este J, James W, Henson GW, Desmyter J, Anne J, De Cl: The bicyclams, a new class of potent human immunodeficiency virus inhibitors, block viral entry after binding 4. Antiviral Res 1996, 29:209-219.

37. Schols D, Este JA, Cabrera C, De CE: T-cell-line-tropic human immunodeficiency virus type $I$ that is made resistant to stromal cell-derived factor lalpha contains mutations in the envelope gp I 20 but does not show a switch in coreceptor use 32. J Virol 1998, 72(5):4032-4037.

Publish with Biomed Central and every scientist can read your work free of charge

"BioMed Central will be the most significant development for disseminating the results of biomedical research in our lifetime. "

Sir Paul Nurse, Cancer Research UK

Your research papers will be:

- available free of charge to the entire biomedical community

- peer reviewed and published immediately upon acceptance

- cited in PubMed and archived on PubMed Central

- yours - you keep the copyright

Submit your manuscript here:

http://www.biomedcentral.com/info/publishing_adv.asp
BiolMedcentral 